\title{
EL NAIXEMENT DE L'IMPOST DEL MORABATÍ AL REGNE DE VALÈNCIA (1265-1266)
}

\author{
Vicent Baydal Sala \\ InStitució Milà i Fontanals (CSIC-Barcelona)
}

\begin{abstract}
Resumen: La instauración del monedatge o morabatí, el impuesto pagado para asegurar la estabilidad de la moneda real, tiene un origen concreto en el reino de Valencia que no ha sido destacado hasta el momento: la financiación de la campaña militar llevada a cabo por Jaime I entre 1265 y 1266 contra los andalusíes sublevados en el reino castellano de Murcia. Además, el análisis del impuesto sobre la moneda en el conjunto de la Corona de Aragón indica que su implantación territorial estuvo estrechamente ligada al proceso de extensión del poder de la monarquía feudal a través de la guerra y de la negociación con los estamentos de cada reino.
\end{abstract}

Palabras clave: Corona de Aragón, Jaime I, fiscalidad, moneda, dinero, relación de poderes.

Abstract: The introduction of monedatge or morabati, the tax paid to ensure the stability of the royal coinage, has a specific origin in the kingdom of Valencia which have not been emphasized so far: the financing of the military campaign leaded by James I between 1265 and 1266 against the revolted Andalusian in the Castilian kingdom of Murcia. In addition, the analysis of tax-money throughout the Crown of Aragon shows that its territorial introduction was closely related to the expansion of the power of feudal monarchy through the war and the negotiation with the estates of each kingdom.

Keywords: Crown of Aragon, James I, taxes, coinage, money, power relationship.

Els furs valencians redactats en temps de Jaume I eren explícits, fer moneda sense l'autorització reial o falsejar-la constituïen un crim de lesa majestat que es 
pagava amb la mort: Aquells qui faran moneda també d'aur com d'argent sens volentat nostra, sens tot remey sien penjats, e encara aquells qui aquella moneda falsaran o aquells qui la fabregaran falsa o la faran fabregar ${ }^{1}$.

Fins i tot el rei se n'ocupà de deixar prova narrativa de la importància d'aquesta qüestió al Llibre dels feits, tot dedicant-hi sis capítols a narrar la perquisició i ajusticiament d'uns falsificadors de moneda burgalesa i jaquesa en els entorns de Tarassona a finals de setembre de 1267. El càstig del feit de la moneda, considerat de gran malefici, fou exemplar: sobre açò haguem a fer justícia de Don Pere Ramírez e de son fill e de Dona Elfa de Tórtoles, e aquests faem-los $n e g a r^{2}$. De fet, aquest episodi reuneix deu dels onze esments al mot «moneda» continguts a la crònica. L'altre hi és ben a prop, nou capítols abans en parlar del plet sorgit a Catalunya entre el vescomte d'Empúries i Ponç Guillem de Torroella sobre la demanda que el comte li faïa de Torroella e postats de castells (e de Rocamaura e de un altre castell) e moneda que devia haver en Torroella, un conflicte que el rei s'havia compromès a jutjar en passar per Girona en setembre de $1266^{3}$.

D'aquesta forma, el Llibre dels feits concentra totes les referències a la paraula «moneda» en aquell any i en aquells pocs capítols, tot i que durant la llarga vida de Jaume I no mancaren altres greus conflictes sobre la circulació monetària ${ }^{4}$. En qualsevol cas, és ressenyable que immediatament abans al primer esment de la crònica havia tingut lloc un altre esdeveniment marcat per les prerrogatives monàrquiques sobre la moneda, en aquest cas al regne de València, tot i que, com és habitual, la crònica l'amaga en tractar-se d'una contribució fiscal del reialenc a una de les campanyes bèl-liques de la monarquia ${ }^{5}$. Així, sabem que

1. «Els Furs», rúbrica CXVI, cap. 7, a LóPez Elum, P., Los orígenes de los Furs en Valencia y las Cortes en el siglo XIII, València, 2001. La rúbrica CXII, cap. 1, del mateix llibre incloïa les mateixes infraccions sobre la moneda com un dels pocs delictes de traïció caracteritzables com a crim de lesa majestat: Aquell fa crim de lesa magestat qui vol liurar la ciutat als enemics o qui aquella volrà cremar o qui volrà aquella de tot en tot destruir o qui se'n passarà als enemichs o qui donarà a aquells ajuda d'armes, d'aver o de consell, o qui s'esforçarà que faça los castells o les viles que són sotsmeses al príncep rebel-les o qui fabregarà falsa moneda o aquella sense manament del príncep batrà o qui fortalees liurarà als enemichs o letres o missatge o alcun senyal a ells trametrà $o \cdot l s$ farà.

2. F. Soldevila (ed.), Les quatre grans cròniques. Llibre dels feits del rei En Jaume, Barcelona, 2007, cap. 471.

3. Ibidem, cap. 457.

4. Com el que s'esdevingué en $1254 \mathrm{amb}$ el bisbe de Vic: Jaume I ordenà als moneders osonencs que aturaren la fabricació de nova moneda episcopal, el que portà al bisbe Bernat de Mur a demanar la confirmació papal. Gudiol, J., «Les bregues sobre lo senyoriu de Vich en temps del rey en Jaume I», a Congrés d'Història de la Corona d'Aragó dedicat al rey en Jaume I y la seua època, Barcelona, 1909, p. 200.

5. La crònica jaumina només parla de les contribucions fiscals dels seus vassalls en casos excepcionals, com les quèsties demanades a les viles reials de Catalunya i Aragó per a escometre el setge final de Balansiya en 1237 , el bovatge obtingut de la generalitat d'estaments catalans en 1264 per a la campanya murciana o 
en abril de 1266, tot just abans de partir cap a Catalunya, Jaume I celebrà una reunió amb els prohoms de les principals viles reials valencianes en què s'aprovà el pagament periòdic i perpetu del monedatge o morabatí, un tribut que assegurava l'estabilitat de la moneda reial de València, com a culminació d'un episodi de negociació politicofiscal associat a l'expedició vers els andalusins de Múrcia revoltats contra el domini castellà d'Alfons X el Savi.

Aquest és, doncs, el naixement de l'impost del morabatí al regne de València, l'origen concret del qual havia estat associat fins ara al pagament de la confirmació dels Furs de València realitzada per Jaume I en 1261, segons l'explicació oferida per Felip Mateu i Llopis, i recollida posteriorment per Pedro López Elum en la seua tesi sobre dit impost ${ }^{6}$. Tanmateix, l'assemblea parlamentària celebrada llavors generà el seu propi donatiu ${ }^{7}$, mentre que l'aprovació del monedatge en 1266 estigué clarament lligada a la guerra contra els musulmans del territori murcià.

Per això, ací exposarem en primer lloc el context dels preparatius militars i el procés d'obtenció de recursos fiscals per part de Jaume I a Catalunya i Aragó, dut a terme entre juny de 1264 i novembre de 1265. Posteriorment, observarem el procés d'institucionalització del monedatge valencià, entre novembre de 1265 i abril de 1266, com a fruit de les necessitats concretes de la monarquia per a la guerra de Múrcia i de la transacció de privilegis amb els prohoms de les viles reials, molt particularment amb els de València. En darrer terme, situarem aquest impost en el marc general de la Corona d'Aragó per tal de particularitzar el seu naixement al regne de València i tractar d'observar les intenses relacions entre guerra, monarquia, moneda i fiscalitat, que rauen entre les causes de la seua imposició.

el subsidi sol-licitat per al projecte de croada de 1269 a la ciutat de Mallorca, que estava exempta de tota demanda segons la seua carta de franqueses. Cf. F. Soldevila, Les quatre grans cròniques..., caps. 230, 387 i 483 .

6. Mateu, F., «Sobre la política monetaria de Jaime I y las acuñaciones valencianas de 1247 y $1271 »$, a Anales del Centro de Cultura Valenciana, XV (1947), p. 249; López Elum, P., El impuesto del morabatí, su base económica y sus aplicaciones demográficas. Datos para su estudio (Siglos XIII-XVIII), València, Tesis doctoral, 1972, p. 21. Robert I. Burns proporcionà nombrosos documents sobre la qüestió, però no l'emmarca -ni tampoc era el seu propòsit- en el seu determinat context: BuRns, R.I., Colonialisme medieval: Explotació postcroada de la València islàmica, València, 1987.

7. En 1261 el rei obtingué 100.000 s. dels christianis et sarracenis tocius regni Valencie, pagats pro confirmacione furorum dicti regni i assignats al retorn d'un préstec de $48.000 \mathrm{~s}$. que els prohoms de la ciutat de València feren al rei per a l'avortat projecte de croada a Terra Santa -ad opus viatici quod facturi eramus in partibus ultramarinis. Cf.: BuRns, R.I., Transition in crusader Valencia: Years of triomph, years of war, 12641270, Princeton, 2001, doc. 362 (13.IV.1261); J. CORTÉs (ed.), Liber privilegiorum civitatis et regni Valencie, València, 2001, vol. I, doc. 64 (12.IV.1261). 


\section{L'OBTENCIÓ DE RECURSOS FISCALS A CATALUNYA I ARAGÓ PER A LA CAMPANYA CONTRA ELS ANDALUSINS DEL REGNE DE MÚRCIA (JUNY DE 1264-OCTUBRE DE 1265)}

Com va copsar Robert I. Burns en el seu estudi sobre el subministrament dels exèrcits de l'expedició murciana, els preparatius de construcció naval destinada al cors contra els musulmans documentats als ports catalanovalencians a començaments de 1264 s'encavalcaren a mitjan d'any amb la petició d'ajuda realitzada per la monarquia castellana amb l'objectiu de combatre l'alçament andalusí produït al regne de Múrcia, fronterer amb el de València ${ }^{8}$.

Entre l'any 1262 i el 1264 tropes a cavall zanâta mantingudes pels marínides havien arribat per primera vegada a Al-Andalus des del Magrib. Ho feien gràcies a l'acord entre el primer soldà de la Granada nassarita i el dels Banu Marin instal·lats a Fes, el que va permetre plantar cara a l'avanç triomfal d'Alfons X de Castella, que acabava de fer capitular Cadis, Jerez i Niebla'. D'aquesta manera, perillaven les recents conquestes realitzades per les monarquies feudals cristianes en el terç meridional peninsular. De fet, Jaume I enllaça directament en la seua crònica aquests esdeveniments amb l'expulsió d'al-Azraq del regne de València en 1258, el que assenyala la vinculació directa entre els preparatius militars andalusins i la conservació del domini de les terres valencianes: E, quan venc aenant, que haguem acabat tot lo feit del regne de València e cobrat ço que haviem perdut, anam-nos-en en Aragó. E haviem oït, d'abans, que el rei de Castella s'era desavengut ab lo rei de Granada, e que el rei de Granada de llong temps havia percaçats los moros d'allèn mar, e que passaven los genets en sa terra, que allèn porien cobrar tota la terra del rei de Castella, e tot ço que havien perdut per nós ne per null altre hom del món en tota l'Andalusia ${ }^{10}$.

Així, tal vegada per aquest clima previ d'enfrontament amb els nassarites i els marínides, ja a començaments de 1264 trobem a la Cancelleria jaumina les primeres notícies sobre la formació d'un estol de galeres, quas in subsidium et defensionem christiane fidei contra sarracenos proposuimus adarmare, a les ordres de Pedro Fernández, fill natural del rei ${ }^{11}$. En aquest sentit, sabem de l'armament

\footnotetext{
8. Burns, R.I., «The crusade against Murcia: Provisioning the armies of James the Conqueros, 1264-1267», a H.H. Hames (ed.), Jews, Muslims and Christians in and around the Crown of Aragon. Essays in honour of Professor Elena Lourie, Leiden, 2004, p. 35-73.

9. GARrido, J. D., Jaume I i el regne de Múrcia, Barcelona, 1997, p. 46-47.

10. F. Soldevila (ed.), Les quatre grans cròniques..., cap. 378.

11. A. Huici i M ${ }^{\text {a }}$.D. Cabanes (eds.), Documentos de Jaime I de Aragón, València, 1976-1988, doc. 1381 (6.II.1264).
} 
de dues galeres per part de la ciutat de Barcelona ${ }^{12}$, una galera de l'arquebisbe de Tarragona $^{13}$, una altra del bisbe de Barcelona ${ }^{14}$, una de l'infant Pere ${ }^{15}$ i una altra feta apud Valenciam ${ }^{16}$. L'armament d'aquesta darrera, a més, anava a càrrec dels prohoms de la capital del regne, com veiem quan Jaume I reconegué dos deutes de $3.000 \mathrm{~s}$. i $4.000 \mathrm{~s}$. al ciutadà valencià Arnau de Font per a comprar xarxes i altres estris necessaris ${ }^{17}$, així com també en el moment en què el rei assegurà als prohoms de la ciutat que faria complir les assignacions ordenades pel batlle Gil Ximénez sobre les rendes i eixides de la ciutat i del regne de València per tal de pagar el préstec que aquells havien fet ad opus galearum ${ }^{18}$.

Així doncs, al llarg de la primavera de 1264 s'estava armant almenys una galera a la ciutat de València, com confirma l'absolució de tota pena d'homicidi a Bernat Sabater a canvi d'enrolar-se in presenti armamento quod contra sarracenus mandamus fieri hoc anno ${ }^{19}$. Per això, és possible que aquell fet estigués relacionat amb la concessió, a començaments de juny d'aquell any, d'un privilegi que donava llicència a la ciutat per a triar quatre prohoms en cada quèstia $o$ servei reial i veïnal amb la finalitat de rebre el jurament dels que estaven obligats a contribuir-hi i, en cas que s'assabentaren de l'ocultació de la veritat en la declaració dels seus béns, pogueren taxar-los segons el seu propi criteri. En conseqüència, sembla factible que, amb l'objectiu de pagar el préstec realitzat pels prohoms valencians per a armar la galera, fos demanada una quèstia que ocasionà certs fraus, una situació que portaria a l'establiment d'una comissió

12. Ibídem, doc. 1385 (2.III.1264). Jaume I eximí els prohoms i la universitat de Barcelona de tot ribatge i quinta d'allò que prengueren als musulmans. A més a més, el rei reconegué un deute de $5.970 \mathrm{~s}$. a Guillem Gruny i Benvenist de Porta, batlles de Barcelona, per les veles i xarxes de cànem comprades per a la construcció de les galeres: ACA (Arxiu de la Corona d’Aragó), C (Cancelleria), reg. 14, f. 62 (27.VII.1264).

13. ACA, C, reg. 14, f. 60 (13.VII.1264). En aquest cas el rei també concedí als procuradors de l'arquebisbe de Tarragona que no reclamaria cap part d'allò que la galera prengués.

14. ACA, C, reg. 12, f. 141 (4.II.1264). El monarca atorgà al bisbe de Barcelona llibertat de moviments -non teneatur esse in conserva aliarum galearum - per a la galera que havia d'armar contra sarracenos ad instanciam et preces nostras, i li assegurà que no faria treves amb els musulmans almenys des del 30 de novembre fins passat un any, bo i podent quedar-se tot allò que guanyés com a botí.

15. A. Huici i Mª.D. Cabanes (eds.), Documentos de Jaime I de Aragón..., doc. 1400 (29.V.1264). La galera que havia d'armar l'infant Pere també rebé autorització per a actuar lliurement en els mateixos termes en què havia estat declarat per a la del bisbe de Barcelona.

16. Burns, R.I., Transition in crusader Valencia..., doc. 535 (29.III.1264).

17. Ibídem, docs. 576 (13.VII.1264) i 555 (26.V.1264). També el jueu Adam de Paterna havia prestat $3.000 \mathrm{~s}$. amb la mateixa finalitat: Ibídem, doc. 554 (26.V.1264).

18. Ibidem, doc. 582 (3.VIII.1264).

19. Ibidem, doc. 544 (11.V.1264). 
que en endavant s'encarregaria de vetllar per la correcta taxació dels béns dels contribuents $^{20}$.

Poc després, cap a finals de juny, Jaume I rebé prop d'Osca una demanda d'ajuda de la seua filla Violant, consort del rei de Castella, per tal de lluitar contra els musulmans que, amb l'ajuda del soldà de Granada i els guerrers marínides, s'havien alçat en les terres andalusines acabades de guanyar i en el regne de Múrcia, sota dominació castellana des de 1243: que tota la terra per poc, de poca en fora, los havien los moros tolta, e que ens pregava, con a pare e a senyor en qui ella havia fiança e sa esperança, que nós que li ajudàssem, sí que ella no vis son marit ne sos fills desheretar en sos dies ${ }^{21}$.

Tanmateix, el consell donat pels rics homes aragonesos al rei va ser, d'una banda, que reunís Corts dels seus regnes e ab consell d'ells que faça ço que fer vol, i, d'altra banda, que aprofités per a cobrar los torts que el rei de Castella li fa. Contràriament, però, la reacció de Jaume I fou la de convocar Corts, però no per a demanar consell sinó directament l'ajuda monetària necessària per a la guerra, ja que considerava que l'auxili sol-licitat s'havia de prestar incondicionalment per tres raons: per a no fallir sa filla, per a no tenir com a enemic el rei de Castella, i, la que és pus fort de tots, per la defensa de les terres pròpies, car si Alfons X perdia les seues, mal estaríem nós ça, en aquesta terra nostra, en clara referència al fronterer regne de València ${ }^{22}$. I, de fet, quasi immediatament veiem que el rei ordena al seu fill Pedro Fernández la custòdia dels castells valencians meridionals de Cocentaina, Relleu, Ibi i Bocairent, quousque guerra regis Castelle et regis Granate penitus sit finita ${ }^{23}$.

Per altre costat, el fet que la preparació de galeres fos anterior al mateix alçament dels andalusins, el qual començà entre el 19 de maig i el 5 de juny

20. J. ConTés (ed.), Liber privilegiorum civitatis et regni Valencie..., doc. 70 (4.VI.1264). El regest fet per Josepa Cortés indica que el privilegi es donava per a elegir quatre prohoms que taxaren els béns dels contribuents per sou i per lliura en les contribucions reials i veïnals. Tanmateix, la tenor estricta del document és la que hem exposat, puix aquella facultat de triar els taxadors de les talles ja havia estat traspassada en l'any 1252: Ibídem, doc. 46 (12.II.1252).

21. F. Soldevila (ed.), Les quatre grans cròniques..., cap. 379. Malgrat que la crònica indica que la visita es produïa aproximadament per Rams, el que correspondria al 13 d'abril de 1264, la revolta andalusina començà a finals de maig i les dades que proporciona l'itinerari reial són irrefutables per tal fixar l'encontre a finals de juny: el 24 de juny el rei sojornà per primer cop aquell any a Sijena, on rebé notícies del missatger de la reina Bertran de Vilanova, i el 29 de juny estava a Osca, on tingué consell amb els rics homes aragonesos sobre la qüestió; per tant, la reunió amb Violant s'hagué de produir necessàriament en aquell interval. De fet, l'1 de juliol el rei ja donava el salconduit a Bertran de Vilanova per tal que portés sa filla a la cort de Castella. Cf.: Miret, J., Itinerari de Jaume I el Conqueridor, Barcelona, 1918, p. 352-353.

22. F. Soldevila (ed.), Les quatre grans cròniques..., cap. 382.

23. BuRns, R.I., Transition in crusader Valencia..., doc. 572 (1.VII.1264). 
de 1264 segons establí Juan Torres Fontes ${ }^{24}$, ha d'implicar necessàriament que aquell estol va ser organitzat per a realitzar expedicions marítimes de saqueig contra els musulmans o en previsió de possibles hostilitats davant les notícies sobre l'entrada dels zanâta a Granada, com poden indicar també altres fonts ${ }^{25}$. De fet, fins a l'inici efectiu del conflicte el rei concedí llibertat de moviments a les galeres que s'havien d'armar, però des d'aleshores ja no hi trobem més notícies al respecte, sinó que, contràriament, només a partir de llavors els documents reials passen a parlar explícitament de l'expedició contra regem Granate et alios inimicos fidei christiane ${ }^{26}$. Aquest fet, doncs, confirma el transcurs dels esdeveniments tal com l'hem exposat: des de principis de 1264 la preparació de galeres que havien de combatre els musulmans per lliure, i des de l'estiu la configuració d'una campanya concreta vers els andalusins revoltats contra Alfons X de Castella al regne de Múrcia.

Això concorda, efectivament, amb la multiplicació de notícies sobre quèsties i subsidis a Catalunya durant el mes de setembre de 1264, després que la reina Violant sol-licitara l'ajuda militar de son pare ${ }^{27}$. Així mateix, a començaments de novembre, després del refús inicial que havia rebut dels aragonesos, Jaume I convocà Corts als catalans per a demanar-los el seu auxili monetari, però aquells, encapçalats pel vescomte de Cardona, el condicionaren a la prèvia resolució dels greuges acumulats. El rei tornà a recordar el perill que corrien les noves terres guanyades al sud -si el rei de Castella perdia lo seu, major embarg hauriem nós e ells de retener lo nostre, que ara no hauriem ${ }^{28}$, tot i que, davant la insistència a

24. Torres Fontes, J., La reconquista de Murcia en 1266 por Jaime I de Aragón, Múrcia, 1967, p. 78-80. Com va fer notar aquest mateix autor (p. 61) el fet que la crònica d'Alfons X indiqués equivocadament que l'alçament es produí en 1261 va fer errar Zurita en la datació dels esdeveniments, qui, per exemple, situà la petició d'ajuda de la reina Violant en 1263. També José Luis Villacañas proposa aquest any, però, com acabem d'assenyalar, les dades disponibles no deixen lloc al dubte sobre la datació en 1264. VILLACAÑAs, J.L., Jaume I el Conquistador, Madrid, 2003, p. 568-569.

25. Zurita afirma que el mestre de l'orde de Calatrava demanà a Jaume I que enviés socors a la frontera el 7 de març de 1263. Atenent a l'esmentada datació incorrecta del cronista aquesta petició potser s'hauria de situar en març de 1264, quan encara no s'havia produït l'alçament andalusí però potser ja es preveien els enfrontaments. Zurita, J., Anales de la Corona de Aragón, Saragossa, 1970, Llibre III, cap. LXV.

26. Burns, R.I., Transition in crusader Valencia..., doc. 574 (10.VIII.1264). El rei autoritzà tots els homes de les seues terres, tant cristians com jueus, a prestar diners al castellà d'Amposta per a l'esmentada expedició.

27. Sabem de diverses regulacions sobre les quèsties de Tuluges, Vilafranca del Conflent, Tuïr, Quart, Serdinyà, Flassa, Joncet i Marinyans, segurament ordenades poc després de la seua petició: ACA, C, reg. 13, f. 218

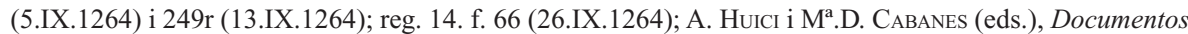
de Jaime I de Aragón..., docs. 1429 i 1430 (16.IX.1264). Així mateix, sabem del reconeixement reial del subsidi de $17.000 \mathrm{~s}$. concedit pel bisbe i el capítol d'Elna per a la guerra contra els musulmans: ACA, C, reg. 13, f. 225 (21.IX.1264)

28. F. Soldevila (ed.), Les quatre grans cròniques..., cap. 384. 
negar el donatiu, Jaume I abandonà l'assemblea, una situació que finalment forçà la cessió dels assistents. D'aquesta manera, les Corts aprovaren l'atorgament del bovatge, un impost directe pagat pels vassalls de totes les senyories en funció dels seus béns immobles, semovents i mobles, i que era concedit com a subsidium seu adjutorium segons la carta d'indemnitat dels nobles, la qual especificava, a més a més, que la seua donació no generava cap tipus de dret per a la monarquia i que els successors de Jaume I només podrien demanar el bovatge quem habere debent tempore suorum regiminum, és a dir, una vegada per regnat en accedir al tron ${ }^{29}$.

Resolta 1'aportació fiscal catalana, el rei marxà immediatament a Saragossa, on reuní en Cort als bisbes e als rics hòmens aragonesos encara en desembre d'aquell any, 1264. Jaume I tractà de convèncer-los perquè li atorgaren la seua ajuda bo i exposant-los, d'un costat, el guany que finalment obtindrien -per un morabeti que vós hi metats del vostre, nós vos en darem deu-i, d'altre costat, insistint novament en el risc que corrien les terres recentment guanyades: si el rei de Castella perdia el seu, poríem perdre nós el nostre. Posteriorment, parlà en privat amb els principals rics homes aragonesos del bovatge que havien aprovat els nobles i eclesiàstics catalans a recaptar sobre els hòmens llurs, però aquells es negaren en boca de Ximén de Urrea: No sabem, en esta terra, senyor, què s'és bovatge. El rei els recriminà la seua negativa a col-laborar malgrat tenir assignades la major part de les rendes reials a través del sistema feudovassallàtic d'honors i cavalleries -vosaltres, que tenits nostra honor, qui trenta mília, qui vint mília, qui quaranta mília sous, bé ens deuríets ajudar-i tractà de fer que almenys consentiren aparentment el subsidi e no ens donets res del vostre, per ço que no ho perdam dels clergues ni de les òrdens ni dels cavallers ${ }^{30}$.

Tanmateix, tot i que la crònica les esmenta molt parcialment, les causes del malestar dels magnats aragonesos amb el rei ultrapassaven el desacord per la campanya murciana i, segons narra Zurita, aquells aprofitaren l'ocasió per a exposar els seus greuges i reivindicacions, entre les quals, es trobaven la unió de Ribagorça a l'Aragó, la revocació de la concessió del rang de ric home, com a

29. A. Huici i Mª.D. Cabanes (eds.), Documentos de Jaime I de Aragón..., doc. 1441 (12.XI.1264). El mateix dia el rei assignà totes les rendes de Montpeller a l'infant Jaume en auxili de l'exèrcit que estava organitzant contra els musulmans: ACA, C, reg. 13, f. 241 (12.XI.1264). Sobre el tribut del bovatge vegeu: P. OrTí, «La primera articulación del Estado feudal en Cataluña a través de un impuesto: el bovaje (ss. XII-XIII)», a Hispania, LXI/3, n. 209 (2001), p. 967-997.

30. F. Soldevila (ed.), Les quatre grans cròniques..., cap. 388, 390 i 392. Sobre el sistema d'honors i cavalleries, que acabà absorbint pràcticament totes les rendes reials ordinàries d'Aragó a finals del segle XIII, vegeu: Canellas, A., Doce documentos fiscales aragoneses del siglo XIII de la alacena de Zurita, Saragossa, 1983; BAYDAL, V., ««Que vengués a emparar et reebre los dits regnes e terres sues». La naturaleza diversa de los pactismos territoriales de la Corona de Aragón a la llegada al trono de Jaime II (1291-1293)», a IV Simposio Internacional de Jóvenes Medievalistas de Lorca, Lorca, 2008, en premsa. 
casta tancada, a Ximén Pérez de Arenós pels seus serveis en la conquesta del reialme valencià, i la vigència del Fur d'Aragó en aquell mateix regne, així com el repartiment de les rendes i terres valencianes en cavalleries ${ }^{31}$. En conseqüència, rics homes i cavallers abandonaren Saragossa i es concentraren a Alagón i Mallén, mentre que Jaume I se'n anà a Calataiud per a finalment partir cap a Catalunya en febrer de 1265, segurament amb l'objectiu de mobilitzar l'ajuda militar necessària de les viles i nobles catalans en l'expedició contra els musulmans $^{32}$.

A finals d'abril el rei tornà a Aragó i hagué de cedir a les reivindicacions dels barons aragonesos: d'una banda, els concedí que el Fur d'Aragó fos observat als seus llocs del regne de València ${ }^{33}$, i, d'altra banda, en una assemblea celebrada a Ejea, aprovà uns furs que establien, entre d'altres coses, la renúncia al cobrament de qualsevol bovatge, la institucionalització del Justícia d'Aragó com a jutge entre el rei i els nobles, la franquesa fiscal dels béns immobles de reialenc adquirits pels cavallers infançons, i l'obtenció de la salva d'infançonia -que eximia del pagament de les peites- mitjançant el testimoni de dos cavallers qualssevol ${ }^{34}$. No obstant això, alguns rics homes com el fill del rei, Fernando Sánchez de Castro, Ferriz de Lizana o Bernat Guillem d'Entença persistiren en la seua oposició i Jaume I convocà la host dels barons catalans i dels homes de Lleida, Almenar, Tamarit i altres llocs propers per a combatre'ls. Així, pel juny, es produïren diversos xocs als voltants de Montsó que conduïren finalment a la signatura d'una treva i la convocatòria d'una nova reunió a Saragossa, celebrada en setembre d'aquell any, $1265^{35}$.

Al remat, la solució del conflicte fou ajornada mitjançant treves generals, el que permeté a Jaume I partir cap a terres valencianes, tot i que amb escassa par-

31. ZurITA, J., Anales de la Corona de Aragón..., Llibre III, cap. LXVI.

32. Miret, J., Itinerari de Jaume I..., p. 366-370

33. Zurita, J., Anales de la Corona de Aragón..., Llibre III, cap. LXVII: En el hecho del fuero que se había de seguir en el reino de Valencia, el rey otorgó sus privilegios a algunos aragoneses que tenían lugares en aquel reino, para que fuesen juzgados a fuero de Aragón.

34. González Antón, L., Las Cortes de Aragón, Saragossa, 1978, p. 50; Canellas, A., «Fuentes de Zurita, Anales III, 67. Las asambleas de Calatayud, Huesca y Ejea de 1265», a Revista de Historia Jerónimo de Zurita, 31-32 (1978), p. 7-41. Anteriorment, els cavallers que testimoniaven la infançonia havien d'ésser parents paterns del sol-licitant; la reforma de 1265, per tant, obria la porta a l'enfranquiment fiscal d'un gran nombre de pobladors i indica probablement un suport popular dels privilegis obtinguts en Ejea. No obstant això, tot i que es coneixen casos com el dels 338 infançons de Luna del mateix any 1265, Elena Lourie ha remarcat la lentitud a l'hora de recórrer a aquest procediment legal de costós preu: ConTE, A., «A poblazión de Luna circa 1265», a Argensola, 112 (1998-2002), p. 225-242; LouRIE, E., «Seigneurial pressure and the Salva de infanzonía: Larués, Marcuello and Yeste (1300-1329)», a XV Congreso de Historia de la Corona de Aragón, Jaca, 1996, vol. 5, p. 199-208.

35. Miret, J., Itinerari de Jaume I..., p. 378. 
ticipació de la noblesa aragonesa com destaca la crònica: e no hi fo, d'Aragó, sinó Blasco d'Alagó ${ }^{36}$. No obstant això, el rei sí que hi demanà la contribució fiscal de les viles reials del regne d'Aragó, tant de les que estaven sotmeses al pagament de peites anuals com sobretot de les set ciutats -Saragossa, Osca, Jaca, Barbastre, Calataiud, Daroca i Terol-, que eren franques segons els seus furs d'infançonia, però van rebre en aquesta ocasió la demanda d'un total de 135.000 s.j. ${ }^{37}$.

Així, el rei s'aplegà a València amb l'infant Pere a finals d'octubre ${ }^{38}$, havent obtingut abans dels prohoms de Terol una altra important ajuda en cereal i bestiar carregada sobre la comunitat d'aldees de la vila: ells dixeren que els donàssem un porter que anàs ab ells per les aldees, e on que trobassen la cosa, que la's prenguessen; e ells assegurar-ho hien molt bé e farien en guisa que, quan exiríem de València, ho hauriem tot. Així mateix, segons explica el Llibre dels feits, el rei també demanà ajuda als prohoms de València, els quals accediren a donarli'n. No obstant això, la crònica només parla del préstec de pa dels mercaders i del buidatge del que hi havia a les cases de la ciutat -llevat ço que haurà mester a un any-, però amaga l'auxili monetari del reialenc ${ }^{39}$.

En aquest sentit, els períodes que engloben l'estada de Jaume I a València i Xàtiva abans de l'inici imminent de la campanya murciana, des de finals d'octubre a mitjan novembre de 1265 , i posteriorment a València-després d'haver pres la

36. F. SoldeVILA (ed.), Les quatre grans cròniques..., cap. 406. Tanmateix, després de conquerir Múrcia la crònica narra que Jaume I deixà els castells d'Alacant i Villena a càrrec dels nobles aragonesos Artal de Luna i Ximén de Urrea: Ibídem, cap. 456.

37. Un document en què es registraren les quantitats demanades va ser publicat per CANELLAs, A., Doce documentos fiscales..., p. 58-59. Quant a les viles peiteres, malgrat que manquen algunes xifres, la suma total demanada a la resta oscil-lava entre els 83.000 s.j. i els 126.000 s.j. D'altra banda, com era usual, les ciutats franques de peita contribuïren en concepte de redempció d'exèrcit, com ara en el cas dels $20.000 \mathrm{~s}$.j. pagats per Saragossa ratione peticionis exercitus quam vobis faciebamus ad Murciam: A. Huici i M M $^{\mathrm{a}}$.D. CABANES (eds.), Documentos de Jaime I de Aragón...,doc. 1497 (16.V.1266).

38. Miret, J., Itinerari de Jaume I..., p. 379. Uns mesos abans, pel març i pel juny de 1265, l'infant Pere ja havia realitzat algunes ràtzies contra els musulmans de les terres murcianes finançades amb préstecs fets per un bon nombre de ciutadans valencians i pel jueu Adam de Paterna: F. Soldevila, Pere el Gran, Barcelona, 1995, vol. 1, p. 125-130; GARRIDo, J.D., Jaume I i el regne de Múrcia..., p. 76-79. Hi trobem diversos reconeixements de préstecs: a Guillem de Plana, ciutadà de València i batlle de Borriana, per un valor de 11.484 s. 4 d.; a Pere Sanç, ciutadà de València, per un valor de 3.664 s. 4 d.; divuit deutes diferents provinents de préstecs fets a València per Ramon Castellà, Arnau Escrivà, Arnau de Montroig, Mateu de Carreracava, Pere de la Vaixella, Bernat d'Arenys, Domingo de Moià, Pere Morera, Guillem de Na Guilsen, Pere Mercer, Guillem de Peralada, Mengot de Boysal, Ramon de Riusec, Guerau Martí, Bernat Dalmau, Berenguer de Cardona, Pere Ros, Ramon de Poblet, Gallard Mas i Pere Guàrdia, per un valor de 15.720 s.; un altre a Adam de Paterna per valor de 28.100 s.; i també diversos reconeixements de deute per compres -bàsicament cavalls, bestiar i cereal- a mercaders de les viles valencianes. Cf.: R.I. BuRns, Transition in crusader Valencia..., docs. 605 (16.IV.1265), 614 (7.VII.1265), 616-617 (10.VII.1264), 619-621 (12.VII.1265), 622624 (13.VII.1265) i 625 (14.VII.1265).

39. F. Soldevila (ed.), Les quatre grans cròniques..., caps. 407 i 409. 
ciutat de Múrcia- durant la part central del mes d'abril de $1266^{40}$, constitueixen un transcendental cicle de negociació politicofiscal que no ha estat explicat ni destacat fins el moment, tot i tenir importants conseqüències, com ara la creació de l'impost del morabatí i la concessió de destacats privilegis als prohoms de les viles reials valencianes.

\section{LA INSTAURACIÓ DEL MONEDATGE VALENCIÀ (OCTUBRE-NOVEMBRE DE 1265, ABRIL DE 1266)}

A penes arribar Jaume I a València, el 28 d'octubre de 1265, es tancà la venda de les rendes de la batllia de la ciutat pels dos anys següents a canvi de 100.000 s. pagats pel cavaller Arnau de Romaní ${ }^{41}$. Així mateix, un parell de dies després el rei reconegué dos préstecs dels prohoms i la universitat de València, un de 70.000 s. fet a la seua persona i un altre de 30.000 s. a l'infant Pere, el cobrament dels quals quedà assignat sobre la dècima dels clergues dels bisbats de Pamplona, Lleida, Tortosa, Barcelona, Vic, la Seu d'Urgell, Elna i Tarragona, que havia concedit el pontífex per a la campanya contra els musulmans, bo i quedant a càrrec del seu retorn Jaume Sarroca, notari reial, degà de València i fill il-legítim del $\mathrm{rei}^{42}$.

Dos dies més tard, l'1 de novembre, trobem entre els documents de la Cancelleria reial una memòria que parla de les quantitats de diners que es devien assignar, de manera genèrica, sobre el monedatge, un tribut que llavors només existia de forma institucionalitzada a l'Aragó, on es cobrava cada set anys des de $1236^{43}$. De fet, un altre document indica que el monedatge aragonès, com pertocava, s'havia cobrat en setembre de $1264 \mathrm{i}$, per tant, no s'hauria de tornar a recaptar fins a $1271^{44}$. Llavors, a quin monedatge feia referència el document datat l'1 de novembre de 1265? Sembla evident, com veurem tot seguit, que els

40. Miret, J., Itinerari de Jaume I..., 379-380 i 385-386.

41. BuRns, R.I., Transition in crusader Valencia..., doc. 639 (28.X.1265)

42. Ibídem doc. 640 (30.X.1265); Marcos, E., La croada catalana, Barcelona, 2006, p. 125; Del Arco, R., «El obispo Don Jaime Sarroca, consejero y gran privado del rey Don Jaime el Conquistador (noticias y documentos inéditos)», a Boletín de la Real Academia de Buenas Letras de Barcelona, VIII (1916), p. 463-480 i 508-521; IX (1917), p. 65-91.

43. Burns, R.I., Transition in crusader Valencia..., doc. 642 (1.XI.1265) El document, barrejat entre d'altres de diversa data, no indica l'any, però, com explica Robert I. Burns en el regest del document immediatament anterior, la referència a la exida del seynor rey de València deixa com a única datació possible la de l'any 1265: Ibídem, doc. 641 (1.XI.1265).

44. A. Huici i Mª.D. Cabanes (eds.), Documentos de Jaime I de Aragón..., doc. 1392 (10.IV.1264). Jaume I reconeixia haver rebut del mestre del Temple 32.000 s.j. que assignava sobre el monedatge dels llocs de l'orde, quod in festo sancti Michaelis septembris proximo venturo debemus percipere et habere. 
prohoms de València -i potser els d'algunes altres viles ${ }^{45}$ - havien promès que el regne, o si més no el reialenc, pagaria un monedatge, el qual, però, no fou instaurat oficialment fins a l'abril de 1266, en tornar el rei de Múrcia.

La certesa que la promesa incloïa almenys tot el reialenc procedeix del fet que la suma total de les assignacions previstes, $142.150 \mathrm{~s}$, , era massa alta com per a referir-se únicament a la ciutat de València. En aquest sentit, segons la carta posterior de creació de l'impost, el monedatge valencià consistia en el pagament d'un morabatí -fixat en 7 s.- per cada casa els béns de la qual superaren els 15 morabatins, és a dir, $7 \mathrm{~s}$. per cada unitat familiar amb patrimoni igual o superior als $105 \mathrm{~s}$. En conseqüència, la previsió de recaptar com a mínim uns $140.000 \mathrm{~s}$. implicava l'existència d'almenys 20.000 focs contribuents, sense comptar els que no arribaven al límit fixat o nichils, que segons les dades analitzades per Pedro López Elum per a les darreries del segle XIV i començaments del XV es poden calcular en una mitjana aproximada del $13,5 \%{ }^{46}$. És per això que hauríem d'aventurar un mínim de 22.700 focs.

La ciutat de València, en canvi, com va calcular raonadament i de forma coherent Josep Torró no devia albergar cap a l'any 1270 més de 5.000 focs cristians, a un índex de 4 persones per foc. Segons aquesta mateixa proposta la resta del reialenc cristià podia rondar els 7.500 focs, mentre que els de senyoriu no sobrepassarien el nombre de 2.250, un 15\% del regne cristià ${ }^{47}$. Desconeixem, però, si el rei aspirava també a recaptar el monedatge dels llocs nobiliaris i eclesiàstics, ja que, tot i que el privilegi posterior establí que l'havien de pagar omnes habitatores civitatis et villarum predictarum et etiam regnorum predictorum pro singulis domibus $^{48}$, sabem que almenys durant la segona meitat del segle XIV el rei només cobrava la porció corresponent al reialenc, tot deixant en termes generals que la resta de senyors recaptassen el pagament dins dels seus dominis, com també passava a l'Aragó ${ }^{49}$. Així doncs, incloent únicament el reialenc, podem comptar amb una xifra d'uns 12.500 focs cristians, molt lluny dels vora 22.700 necessaris per tal de col·lectar els 140.000 s. previstos com a recaptació mínima.

45. És possible que una representació dels prohoms de Morvedre s'hi trobara també a València, ja que el rei traspassà llavors a la vila la gestió de les taules de la carnisseria i la pescateria: BuRns, R.I., Transition in crusader Valencia..., doc. 638 (27.X.1265). No obstant això, el fet que els primers privilegis als habitants de Xàtiva no es donaren fins a l'arribada del rei a aquesta vila fa pensar, per altra banda, que els prohoms xativins no eren presents a la capital i que, per tant, els de València encapçalaren la negociació pràcticament en solitari.

46. López Elum, P., El impuesto del morabatí..., p. 453 i 474.

47. Torró, J., El naixement d'una colònia, València, 2006, p. 100-102.

48. J. CoRTÉs (ed.), Liber privilegiorum civitatis et regni Valencie..., doc. 74 (16.IV.1266).

49. López Elum, P., El impuesto del morabatí..., p. 139-169. En el cas dels ordes militars, el rei percebia generalment una meitat i l'orde l'altra meitat. 
No obstant això, cal tenir present que, com es comprova en la següent petició del monedatge en 1273, també els musulmans del rei havien de pagar el morabatí, per la qual cosa s'han d'afegir els seus focs al còmput global. Amb tot, tampoc posseïm estimacions ajustades del seu volum demogràfic més enllà dels 100.000 individus per al conjunt del regne proposats per Josep Torró simplement «com a hipòtesi de treball», el que, potser, elevant l'índex a 5 -tot suposant una densitat residencial més alta-, representarien unes 20.000 cases. No sabem, però, quin percentatge d'aquests focs pertanyia a la jurisdicció reial, tot i que, en funció de l'evolució de les senyories valencianes traçada per Enric Guinot ${ }^{50}$, baixava amb seguretat del $85 \%$ estipulat per als cristians i potser se situava en els volts de la meitat del total de pobladors musulmans. Per tant, tal vegada el rei podia preveure la recaptació de l'impost d'unes 10.000 cases andalusines ${ }^{51}$.

Així doncs, la xifra conjunta de focs cristians i musulmans sobre els quals hem calculat que el rei podria tractar d'ingressar el monedatge, corresponent a un total d'unes 22.500 unitats familiars, s'acosta congruentment als 22.700 focs anteriorment esmentats com a necessaris per a preveure una recaptació d'uns 140.000 s., la suma de les assignacions realitzades sobre l'impost abans que el rei partís cap a Múrcia. Per tant, tot i tenir present l'altíssim grau d'especulació en què ens movem, pensem que els càlculs fets per Torró i els que es desprenen de les assignacions prèvies al monedatge de 1266 s'ajusten d'una forma bastant aproximada; si més no serveixen per a considerar amb total seguretat que les xifres manejades a finals de 1265 sobre el monedatge es referien al pagament realitzat almenys per tot el reialenc, com tractàvem de demostrar.

Fos com fos, la concessió del monedatge quedà acordada a València en novembre de 1265 , el que permeté fer assignacions per a la campanya murciana: $25.000 \mathrm{~s}$. per l'eixida del rei de la ciutat, 20.000 s. per a les galeres, 18.000 s. per 1.500 cafissos de civada per als cavallers de la frontera durant un mes, 11.250

50. Guinot, E., «La creació de les senyories valencianes en una societat feudal de frontera: el regne de València (segles XIII-XIV)», a Revista d'Història Medieval, 8 (1997), p. 79-108.

51. Pensem que el rei tractaria de recaptar el monedatge dels musulmans en el reialenc i en els senyorius eclesiàstics, així com també en els laics sotmesos a la jurisdicció dels termes urbans de les viles reials, ja que en el següent pagament exigit als musulmans per a l'any 1273 -els cristians havien avançat el monedatge en 1271 com a part d'un donatiu de Corts- s'especifica clarament que s'havia de demanar a tots los moros de la església, e de cavalers e altres persones, e que lauraran jovades, sempre i quan no fossen de castels ab tèrmens de richs hòmens o de cavalers o de ciutadans: ACA, C, reg. 18, f. 94v-95r (1.XII.1272). Per tant, el més probable és que ja des de l'inici del monedatge les jurisdiccions senyorials laiques quedarien fora del control reial, mentre que el traspàs total o d'una part de l'exacció als senyorius eclesiàstics, incloent els ordes militars, fou resultat d'un procés gradual de concessions, com palesen les dades oferides per LóPEZ Elum, P., El impuesto del morabatí..., p. 132-133. D'altra banda, sembla que les aljames jueves del regne estaven exemptes del pagament del monedatge, segons certes notícies de finals del segle XIII: ACA, C, reg. 324 , f. 129v (1.IV.1298). 
s. per 4.500 arroves d'oli, 9.000 s. per al vi, 30.000 s. per als castells i $39.000 \mathrm{~s}$. per als mercaders genovesos ${ }^{52}$. Immediatament, el rei partí cap a Xàtiva, on el 8 de novembre concedí, d'una banda, un important privilegi que feia francs de tota exacció reial els prohoms de la vila que tinguessen cavalls per valor de 40 auris amb les seus armadures ${ }^{53}$, i, d'altra banda, atorgà una exempció temporal per cinc anys de tota talla reial a la vila de Xàtiva, atenent a les tasques $i$ enormes despeses que ja havia fet i encara feia en la guerra contra els musulmans ${ }^{54}$.

Sense solució de continuïtat, Jaume I entrà en les terres andalusines alçades contra el domini castellà, fent capitular Villena, Elda i Petrer, abans d'arribar cap al 20 de novembre a Alacant, que havia restat sota el control cristià i es convertí en la base d'operacions de l'expedició. Així, a començaments de desembre el rei es desplaçà fins a Alcaraz per a trobar-se amb Alfons X de Castella i pactar les condicions de la conquesta i el repartiment del botí murcià. Acte seguit, camí de Múrcia i durant la segona meitat del mes, Elx capitulà i el rais de Crevillent oferí el seu castell i dos més dels passos muntanyencs del Vinalopó. Finalment, a principis de gener es prengué Oriola i a les acaballes del mes es rendí la ciutat de Múrcia, que Jaume I no abandonà fins el març de 1266, després d'haver procedit a un primer repartiment de cases i terres entre els components del seu exèrcit ${ }^{55}$. El rei passà quasi tot el mes de març a Alacant, on rebé els comptes del batlle de Barcelona que incloïen la quèstia de la ciutat de 60.000 s. $^{56}$, segurament demanada, com hem vist, al llarg de l'any anterior juntament amb la resta de viles de Catalunya. Finalment, a les primeries d'abril, el monarca retornà a València, on sembla que residí únicament entre el 7 i el 20 d'abril ${ }^{57}$.

52. Burns, R.I., Transition in crusader Valencia..., doc. 642 (1.XI.1265). La summa anotada era de 142.150 s., encara que el conjunt de les xifres registrades fan un total de $100 \mathrm{~s}$. més, $142.250 \mathrm{~s}$.

53. Ibidem, doc. 651 (8.XI.1265). Com indica Robert I. Burns si amb el mot «auri» (aureum) es feia referència al morabatí alfonsí el valor total, segons la taxació d'aquesta moneda feta en 1247, seria de 240 s., mentre que si es feia referència a la masmudina jucefina equivalia a $160 \mathrm{~s}$.

54. Ibidem, doc. 652 (8.XI.1265): Attendentes et considerantes labores et inmensas expensas quas vos universi et singuli probi homines et habitatores Xative sustinuistis et fecistis racione presentis guerre sarraçenorum, et quos et quas adhuc sustinere et facere opportebit, per nos et nostros enfranquimus et franchos ac liberos facimus, hinc ad quinque annos proximos venturos, vos universos singulos probos homines ac habitatores Xative presentes et futuros, cum omnibus bonis vestris vestrorumque habitis et habendis, ab omni peita, questia, cena, exercitu et cavalcata et eorum redempcionibus, et ab omni alia demanda sive exaccione regali.

55. Garrido, J.D., Jaume I i el regne de Múrcia..., p. 80-82 i 106-114; VillaCAÑas, J. L., Jaume I el Conquistador..., p. 592-598.

56. ACA, C, reg. 15, f. 10v (13.III.1266). A més a més, la ciutat prestà al rei uns altres 60.000 s. a canvi dels quals va quedar eximida de tota exacció reial fins que la monarquia tornés els diners: ORTí, P., Renda $i$ fiscalitat en una ciutat medieval: Barcelona, segles XII-XIV, Barcelona, 2000, p. 590.

57. Miret, J., Itinerari de Jaume I..., p. 386. 
Durant aquest breu període de temps, a través d'una reunió entre Jaume I i els prohoms d'alguns dels principals nuclis del reialenc -València, Xàtiva, Morvedre i Borriana- es culminà la negociació politicofiscal iniciada en novembre de 1265. Així, el 14 d'abril de 1266 fou publicat un privilegi segons el qual, a canvi de l'estabilitat de la moneda reial valenciana, s'instaurava un monedatge pagat imperpetuum a proximo venturo festo Natalis Domini in septem annos, et ex tunc de septennio in septennium imperpetuum dicto festo ${ }^{58}$. La tenor del document, doncs, establia que el tribut no es pagaria llavors sinó set anys després de la festa de Nadal de 1266, és a dir, pel Nadal de 1273.

Tanmateix, això no implicava que en aquella ocasió no es pagués, com interpretà Josep Torró ${ }^{59}$, o que es fes en 1267, com afirmà Pedro López Elum a partir d'una anotació marginal realitzada en un trasllat del privilegi, ${ }^{60}$ sinó que aquesta peculiaritat aparent del privilegi - que no establia el pagament immediat de l'impost- responia al fet que aquest ja s'estava pagant, amb quasi total seguretat des de les darreries de 1265, poc després d'haver estat concedit a València entre finals d'octubre i 1'1 de novembre, dia en què es preveien les primeres assignacions sobre el seu futur rendiment. De fet, només d'aquesta manera és possible que aproximadament un any després, en gener de 1267, Jaume Sarroca retés els comptes dels diners del monedatge col-lectats en els llocs del regne citra Xucarum $^{61}$, tot i que els dels llocs ultra Xucarum, recaptats pel porter major Bonanat de Guia, encara tardarien un altre any a ser retuts, pel maig de 1268, durant la següent estada del rei a València ${ }^{62}$.

58. J. CoRTÉs (ed.), Liber privilegiorum civitatis et regni Valencie..., doc. 74 (14.IV.1266).

59. Torró, J., «Colonització i renda feudal. L'origen de la peita al regne de València», a M. SÁnCHEz, A. Furió I P. Bertran (eds.), Col-loqui «Corona, municipis i fiscalitat a la Baixa Edat Mitjana», Lleida, 1997, p. 482, nota 32. Segons hi diu, el monedatge «es recapta per primera vegada, després de pactar amb les Corts un avançament, en 1271». D'altra banda, aquest mateix autor, que tractà la qüestió de forma merament tangencial, considerà erròniament en el mateix article que les assignacions no datades sobre el monedatge de novembre de 1265 corresponien a 1262-1263.

60. López Elum aporta una nota d'un trasllat d'època de Pere el Cerimoniós del privilegi de 1266, en què s'hi afegeix: Et sic a festo Natalis Domini anni MCCLXVII in septem anos, et sic erant sive solvendum in festo natalis domini anni MCCLXXIII et ex tunc de septenio in septenio: ARV, Reial 613, f. 99v, citat per LóPEZ Elum, P., El impuesto del morabatí..., p. 27-28. Això quadra amb la hipòtesi de l'autor segons la qual, malgrat la claredat del privilegi, en què es parlava de septennis, el pagament del monedatge es feia de forma sexennal, ja que «los septenios establecidos contaban el último año de tal septenio como séptimo y como primero del siguiente ciclo» (p. 31). Tanmateix, això esdevé cert només a partir del regnat del Cerimoniós, ja que amb anterioritat, durant el segle XIII i almenys fins al regnat d'Alfons el Benigne, la periodicitat del monedatge era septennal com es pot comprovar, per exemple, als registres 304 i 538 de la Cancelleria reial.

61. BuRns, R.I., Transition in crusader Valencia..., doc. 709 (9.I.1267). El document parla tant de les despeses quas fecistis in colligendo monedatico regni Valencie citra Xucarum, com del retiment dels diners del monedatico regni Valencie citra Xucarum, quod vos pro nobis collegi fecistis et recepistis.

62. Ibidem, doc. 841 (7.V.1268). El compte del monedatge, quod collegistis pro nobis in valle de Albayda et omnibus aliis locis regni Valencie ultra Xucarum, només rendia finalment 1.927 s. 2 d., però després de 
D'altra banda, en contraprestació per l'establiment del morabatí al regne de València, les universitats i especialment els seus prohoms, que havien accedit a la concessió de l'impost en nom d'aquelles, reberen diversos privilegis, precisament a partir del dia següent de la seua institucionalització. En primer lloc, la franquesa perpètua de tota exacció i demanda reial donada ja en novembre de 1265 als ciutadans de Xàtiva que tinguessen cavall per valor de 40 auris $i$ armadura, tornà a ser concedida, especificant ara que aquests ciutadans armats havien d'anar en exèrcit i cavalcada quan la seua ciutat en fes i que havien de fer alardum davant del batlle de la vila una vegada a l'any per Nadal ${ }^{63}$. A més a més, sabem que aquest mateix tipus de franquesa, que equiparava els ciutadans armats als nobles exempts, fou ara atorgat als ciutadans d'Alzira i València, i potser també a Morvedre i àdhuc a totes les viles de reialenc ${ }^{64}$. Igualment, també en aquest moment o potser ja en novembre de 1265 -com havia passat aleshores amb Xàtiva- la universitat de València rebé una franquesa temporal de quatre anys de tota exacció reial, que només coneixem a través d'una pròrroga anual de febrer de $1268^{65}$.

Així mateix, Jaume I concedí dos privilegis de notable importància per a la concentració de poder en mans dels prohoms de la ciutat de València. Per un costat, institucionalitzà l'existència dels quatre jurats ciutadans encarregats de regir, governar i gestionar els afers de la universitat, amb potestat per triar els consellers que estimaren oportuns i ser elegits anualment pels jurats i consellers ixents ${ }^{66}$. Per altre costat, tot especificant que el privilegi es concedia propter plurima grata servicia que nobis exibuistis, a partir d'aleshores els jurats i prohoms de València podrien proposar una terna de candidats entre els quals el rei o el batlle escollirien anualment l'important càrrec de justícia de la ciutat ${ }^{67}$.

descomptar els nombrosos pagaments ordenats pel rei: computatis omnibus solucionibus, datis et expensis quas inde fecistis pro nobis aliqua racione.

63. Martínez Ferrando, J.E., Catálogo de la documentación relativa al antiguo Reino de Valencia, contenida en los registros de la Cancillería Real, Madrid, 1934, doc. 628 (15.IV.1266).

64. J. CoRTÉs (ed.), Liber privilegiorum civitatis et regni Valencie..., doc. 75 (15.IV.1266); A. HuICI i Mª.D. Cabanes (eds.), Documentos de Jaime I de Aragón..., doc. 1494 (18.IV.1266). Pel que fa a Morvedre sabem que en 1279 els ciutadans armats hi gaudien de la franquesa, ja que Pere el Gran ordenà al procurador del regne que els hi la fes respectar: ACA, C, reg. 41, f. 118 (26.VII.1279). En conseqüència, és possible que, encara que no tinguem constància documental, aquella exempció fos vàlida a tot el reialenc o, si més no, a les viles més importants del regne.

65. Burns, R.I., Transition in crusader Valencia..., doc. 754 (13.II.1268).

66. J. CoRTÉs (ed.), Liber privilegiorum civitatis et regni Valencie..., doc. 78 (15.IV.1266). Com ha estat remarcat per Rafael Narbona aquest privilegi atorgà caràcter perpetu a l'organització política i administrativa dels jurats, que venien actuant de forma provisional des de 1245: NArBona, R., Valencia, municipio medieval. Poder politico y luchas ciudadanas. 1239-1418, València, 1995, p. 27.

67. J. CoRTÉs (ed.), Liber privilegiorum civitatis et regni Valencie..., doc. 77 (15.IV.1266). 
D’aquesta forma, a penes uns dies després de la concessió d'aquests privilegis, el rei marxà cap a Catalunya, amb el que es pot donar per conclòs aquest cicle de negociació que comportà importants canvis en la història fiscal i política del regne. D'un cantó, el rei obtingué diners per a la campanya murciana i aconseguí la instauració del morabatí, un tribut perpetu i pagat teòricament de forma general. De l'altre cantó, els ciutadans de les principals viles obtingueren l'enfranquiment en les quèsties i exaccions reials si podien oferir el seu servei militar i, si més no els de València, guanyaren importants quotes de poder en quedar el regiment i la justícia de la ciutat sota el seu control a través de la institucionalització d'un govern de quatre jurats ciutadans, amb possibilitat de triar els seus consellers i la proposició d'una terna per al càrrec de justícia.

\section{GUERRA, MONEDA, FISCALITAT REIAL I RELACIONS DE PODER A LA CORONA D'ARAGÓ DURANT EL SEGLE XIII}

El retiment de comptes presentat en gener de 1267 per Jaume Sarroca, qui com hem vist havia quedat encarregat de retornar els préstecs de $100.000 \mathrm{~s}$. concedits pels prohoms valencians al rei i a l'infant Pere, mostra la varietat de recursos fiscals cercats per la monarquia per tal d'afrontar la guerra contra els musulmans ${ }^{68}$. Així, les xifres presentades pel notari reial relacionades amb la campanya racione frontarie Murcie incloïen, en primer lloc, totes les despeses realitzades des de l'entrada del rei a València a finals d'octubre de 1265 fins al seu retorn cap a Catalunya ja en abril de 1266 -incloent les porcions de la casa reial, de l'infant, de don Juan Manuel i dels rics homes catalans i aragonesos deixats en la frontera-, les del transport de vitualles a Alacant i les de les galeres armades pels prohoms de València i per Carròs de Rebollet. Per altre costat, s'hi presentaven les rebudes del guany de la venda de farina en Múrcia i d'un ariet en Alacant, del forment de les galeres, de les vitualles i diners prestats per mercaders mallorquins, genovesos i d'altres llocs, de les sumes procedents del batlle de València, Arnau de Romaní, i dels prohoms de la mateixa ciutat, del monedatge del regne de València citra Xucarum -col·lectat per Sarroca-, de dons, serveis i préstecs, i de les col·lectes i assignacions reials, tant en diners com en espècie,

68. Precisament la guerra contra haereticos vel paganos -juntament amb la defensione patriae, el rescat del senyor pres en guerra justa i la visita al príncep per obtenir privilegis-era un dels supòsits pels quals Ramon de Penyafort justificava en la dècada de 1230 la imposició de talles per part de la monarquia: PeNYAFORT, R. de., Summa Sancti Raymundi de Peniafort, Roma, 1603, Llibre Segon, V, XI, «Quaestio quarta. Quid de quaestis, vel talleis?», p. 169-173. 
realitzades tam super christianis Aragonie, Catalonie, Valencie et iudeis quam eciam sarracenis ${ }^{69}$.

En conseqüència, com també hem pogut comprovar anteriorment, Jaume I tractà d'obtenir recursos de fonts diverses d'arreu de la Corona, bo i intensificant les seues peticions fiscals en ocasió d'una considerable mobilització militar, qualificada pels nobles aragonesos com de major que la de la batalla de Las Navas de Tolosa, ni altra que anc fos en Espanya ${ }^{70}$. D'aquesta forma, el monarca obtingué ajudes variades del reialenc: peites i redempcions d'exèrcit de les viles i ciutats aragoneses, quèsties de les catalanes, el morabatí de les valencianes i talles dels jueus i musulmans de la Corona. A més a més, hi tractà de fer contribuir la resta de senyories dels territoris que regia; ho aconseguí a Catalunya, a través del pagament del bovatge, i també de l'Església de tota la Corona -mitjançant l'obtenció de la dècima pontifícia per a les croades durant tres anys-, però no així de la noblesa aragonesa, que es negà a aprovar cap tribut general, ni a Aragó ni al regne de València, com observarem posteriorment.

En conjunt, tots aquests recursos percaçats per la monarquia durant any i mig havien d'emprar-se en retornar els nombrosos préstecs rebuts per tal de bastir un nou exèrcit de conquesta ${ }^{71}$. En aquest sentit, podem dir que el lideratge de la monarquia en l'organització d'una campanya militar de grans dimensions serví com a ressort d'intensificació del seu poder sobre el territori, una intensificació expressada en la contribució fiscal de la resta d'estaments, tot i que mediatitzada per la diversa relació de poders present a cadascuna de les unitats polítiques de la Corona.

Per tant, com es pot advertir al llarg del procés de desplegament dels estats monàrquics feudals des del segle XII, la guerra catalitzà notables canvis polítics i fiscals. En el cas concret de l'impost del monedatge, un repàs als seus diversos processos d'institucionalització en els diferents territoris de la Corona d'Aragó - tots ells sota la mateixa forma de tribut perpetu septennal pagat per

69. Burns, R.I., Transition in crusader Valencia..., doc. 709 (9.I.1267). Els documents només expliciten les xifres finals, segons les quals el rei devia a Jaume Sarroca un total de 78.630 s.: Ibídem, doc. 710 (15.I.1267).

70. F. Soldevila (ed.), Les quatre grans cròniques..., cap. 380.

71. Tot i que en desconeixem els detalls, els documents coneguts apunten que la campanya es bastí fonamentalment amb préstecs assignats sobre les contribucions fiscals promeses al rei. Per exemple, a finals de febrer 1266, Jaume I concedí 1licència a Ximén Pérez de Arenós per obligar omnes reditus nostros Aragonie et peitas ac cenas et eciam omnes alios denarios quos a civitatibus et villis Aragonie habere voluerimus de cetero aliqua racione amb els préstecs fets per illis hominibus Aragonie, tam militibus quam aliis, qui nobis nunc in ista tanta necessitate mutuaverint peccuniam suam vel victualia sua: BuRNs, R.I., Transition in crusader Valencia..., doc. 665 (27.II.1266). 
focs $^{72}$ - permet observar que la seua imposició respongué a determinats contextos molt concrets, en què la monarquia hagué d'estipular la seua instauració amb els estaments preponderants a cada regne i actuar en funció del seu propi poder territorial.

En primer lloc, el tribut periòdic sobre la moneda reial jaquesa fou establert en les Corts de Montsó de 1236, reunides per tal de preparar i finançar la conquesta del futur regne de València. Anteriorment, com va destacar Thomas N. Bisson, sabem que durant les dues darreres dècades del segle XII el monarques aragonesos havien emprat el recurs a les rebaixes de llei i les mutacions monetàries com a forma d'obtenir guanys a partir de les seues prerrogatives sobre l'encunyació de moneda. En canvi, durant la segona meitat del regnat de Pere el Catòlic i els primers anys de Jaume I els reis acudiren a les confirmationes monetae -apel-lades també monetatica- com a principal mètode de fer contribuir fiscalment els súbdits aragonesos. Així, el Catòlic demanà un primer monedatge en 1205, mentre que el seu fill obtingué sengles quantitats de tres confirmacions monetàries realitzades en les assemblees parlamentàries de 1218, $1221{\mathrm{i} 1223 .^{73}}^{73}$ En aquest sentit, cal destacar també que potser la franquesa de peites de la qual gaudien les principals ciutats aragoneses des del segle XII induïa la monarquia a cercar fonts fiscals diferents a les talles, unes fonts, a més a més, que incloïen tot el territori aragonès i part del català on circulava la moneda jaquesa.

Contràriament, a Catalunya les principals ciutats no van ser enfranquides del pagament de quèsties fins a finals del segle XIII, i les mateixes Corts de coronació de Jaume I celebrades en 1214 establien que les viles empenyorades per son pare contribuirien amb moderate questie anuals, mentre que les ciutats que volguessen també ho farien amb colllectes pròpies, ja que n'havien quedat eximides, però només temporalment fins que el rei arribés a la pubertat ${ }^{74}$. D'altra banda, el fet que el comte de Barcelona no gaudira a terres catalanes de l'exclusivitat del dret d'encunyació monetària, que havia de compartir amb altres comtes i amb el bisbe de Vic, pot també ajudar a explicar que els reis no estigueren tan interessats en les confirmacions monetàries a Catalunya com a l'Aragó. Per un cantó,

72. Si en el cas del regne de València, com ja hem exposat, el monedatge consistia en el pagament de 7 sous valencians per cada família que tingués béns per valor de 105 sous o més, a l'Aragó es tractava de 7 sous jaquesos per cada patrimoni valorat en 140 sous o més, mentre que al regne de Mallorca implicava la contribució de 8 sous mallorquins per cada foc amb béns valorats en un import igual o superior als 200 sous.

73. Bisson, T.N., Conservation of coinage: Monetary exploitation and its restraint in France, Catalonia, and Aragon (c. A.D. 1000-c. 1225), Oxford, 1979, p. 84-85, 90-96 i 114-115.

74. G. Gonzalvo (ed.), Les constitucions de Pau i Treva de Catalunya (segles XI-XIII), Barcelona, 1994, doc. 23, cap. XXX. Sobre l'enfranquiment de quèstia de les ciutats catalanes vegeu: SÁnchez Martínez, M., El naixement de la fiscalitat d'Estat a Catalunya (segles XII-XIV), Girona, 1995. 
hi podien comptar amb les quèsties de les ciutats reials i, per l'altre, els tributs imposats sobre la moneda barcelonesa no cobrien el conjunt del territori català.

Per exemple, quan Pere el Catòlic exigí en 1205 el pagament del primer monedatge aragonès, que tractava de fer contribuir la generalitat de vassalls del regne $^{75}$, a Catalunya aquesta mateixa petició quedà associada al bovatge, un tribut pagat en reconeixement de la senyoria reial i com a redempció de la pau, que també s'imposava sobre el conjunt de senyories laiques i eclesiàstiques. Així, després que el rei Pere demanara un altre bovatge general en 1211 per a la campanya de Las Navas de Tolosa, a l'inici del regnat de Jaume I, en 1217, els magnats catalans n'aprovaren un altre, en aquesta ocasió segons diu Zurita, en reconocimiento de su señorío ${ }^{76}$. Per tant, com hem vist abans en ocasió de la concessió del bovatge de 1264, es considerava que aquesta exacció només podia ser demanada de iure una vegada per regnat, després de l'accessió al tron, ${ }^{77}$ tot i que Jaume I en negociaria tres més per a les corresponents campanyes de conquesta que realitzà durant la seua vida.

D'aquesta manera, mentre que d'Aragó no se'n coneix aportació semblant, en 1228 les Corts catalanes aprovaren el pagament d'un segon bovatge al rei Jaume per a finançar la conquesta de Mallorca, una empresa eminentment catalana. I novament en 1232 n'atorgaren un altre per a la conquesta de València ${ }^{78}$, però en aquest cas l'activa participació de la noblesa i de les ciutats aragoneses sí que es traduí en la concessió d'importants subsidis: la quinta, un impost extraordinari sobre els ramats ${ }^{79}$,

75. Segons Zurita el monedatge volia cobrar-se sin eximir a ninguno aunque fuese infanzón o de la orden del Espital o de la caballería del Temple: ZuRITA, J., Anales de la Corona de Aragón..., Llibre II, cap. LII.

76. Ibídem, Llibre II, cap. LXIX.

77. També en el cas del regne de Navarra els reis rebien un impost a la seua accessió al tron, però en aquest cas es tractava, contràriament d'un monedatge. De fet, la principal prerrogativa reial sobre la moneda navarresa quedà precisament concentrada a l'inici de cada regnat, quan les Corts que havien de jurar el nou monarca concedien, segons el Fur General, el pagament d'un únic monedatge mentre que, alhora, la monarquia realitzava una nova emissió monetària. CARRASCO, J., «Moneda metálica y moneda crediticia en el reino de Navarra (siglos XII-XV)», a Moneda y monedas en la Europa Medieval (siglos XII-XV), Pamplona, 2000, p. 421-422.

78. ORTí, P., «La primera articulación del Estado feudal en Cataluña..., p. 967-997.

79. Només coneixem aquest tribut a través d'esments documentals realitzats en temps de Pere el Gran, quan aquest tractà d'obtenir-lo de forma semblant al bovatge català, en reconeixement de senyoriu, porque esta primera quinta pertenece a nos por dreyto, por razón de nuestro sennorio, bo i tractant de cobrar-la en todos los lugares que son en Aragón dessá Ebre, assí como la moneda jaquesa s'estende. Tanmateix, els prohoms de Saragossa encapçalaren la resistència a aquesta imposició i qüestionaren el fet que Pere el Gran hi tingués dret a cobrar la quinta, tot al·legant que només la concedirien de gràcia, com la que havien donat a son pare por la presón de Valencia. Finalment, els aragonesos aconseguiren en 1283 que el Privilegi General suprimís la quinta d'aqui adelant, ja que nunqua se die en Aragon fueras por priegos a la vuest de Valencia. Cf: A. Canellas (ed.), Colección diplomática del concejo de Zaragoza, Saragossa, 1975, docs. 84 (24.VI.1279) i 104 (6.XII.1279); GonZÁLeZ Antón, A., Las Uniones aragonesas y las Cortes del reino (1283-1301), Saragossa, 1975, vol. II, p. 16. 
i el monedatge, que fou institucionalitzat atenent els interessos tant del monarca, que s'assegurava el pagament d'un impost periòdic, com dels mateixos estaments, que garantien així l'estabilitat de la recentment emesa moneda jaquesa de tern.

Fet i fet, sembla que a la Corona d'Aragó la imposició dels diversos monedatges territorials anà aparellada a l'extensió de la moneda de billó de tres diners de llei. D'un costat, com ha exposat Josep Torró, la moneda reial de Jaca assegurada en 1236 era ternal i s'havia hagut d'encunyar entre 1233 i aquell any, mentre que, d'altre costat, la definitiva invariabilitat de la moneda comtal de Barcelona no arribaria fins que s'hi començà a encunyar moneda de tern, en 1258, moment en què Jaume I, sense que es conega cap contrapartida econòmica, va confiar als prohoms barcelonins el control sobre les encunyacions i es va comprometre a mantenir la moneda immutable perpètuament, a no percebre cap monedatge sobre ella $i$ a què els seus successors juraren aquestes condicions a la seua accessió al tron ${ }^{80}$.

Pel que fa als regnes de València i de Mallorca, el diner reial valencià, de tern, hi fou introduït en 1247 tot decretant la seua utilització exclusiva. Com ha remarcat igualment el mateix Josep Torró, aquesta imposició comportà un important guany per a Jaume I mitjançant l'establiment d'un canvi coercitiu i fraudulent de la resta de monedes en circulació en aquells dos regnes ${ }^{81}$, tot i que, alhora, el mateix rei es comprometé a mantenir-la sense mutacions durant la seua vida $\mathrm{i}$ deu anys més ${ }^{82}$. Tanmateix, com hem exposat, a penes dues dècades després el rei adquirí al regne de València el dret al pagament d'un impost perpetu per tal d'assegurar l'estabilitat de la moneda, precisament en el mateix moment en què obtenia un quart bovatge català i tractava d'aconseguir el pagament d'un tribut similar a l'Aragó ${ }^{83}$.

80. Torró, J., «Colonització i renda feudal...», p. 486; Bisson, T.N., Conservation of coinage..., p. 116-117. Segons Bisson no hi hagué cap confirmació de la moneda barcelonesa des de 1174, quan era quaternal, fins a 1254, quan era doblenca, quatre anys abans de passar a ser ternal. En aquell moment, el rei assegurà l'estabilitat de la moneda per deu anys a canvi d'un subsidi recaptat per formam solidi et libri, almenys a Barcelona i Perpinyà. Ultra això, cal destacar que aquell pagament fou paral·lel a un augment acordat de l'encunyació de la moneda jaquesa i a l'avançament en tres anys del monedatge aragonès -si més no a Lleida-, actes tots ells associats a una altra campanya militar, la de Navarra contra els castellans de 1254 i 1255, com s'explicita als documents: propter guerram quam habemus et speramus habere... inter nos et illustrem regem Castelle. Cf.: A. Huici i M ${ }^{\mathrm{a}}$.D. CABAnes (eds.), Documentos de Jaime I de Aragón..., docs. 640 (13.II.1254), 648 (17.V.1254), 659 (30.VIII.1254) i 666 (9.X.1254).

81. TorRó, J., «L'organització monetària del regne de València al segle XIII (1247-1277)», a Gaceta numismática, 137 (2000), p. 54-57.

82. J. CoRTÉs (ed.), Liber privilegiorum civitatis et regni Valencie..., doc. 24 (8.V.1247). El compromís reial era per tota vita nostra et post per decem annos, i no únicament per deu anys com argumentà LóPEz ELuM, P., El impuesto del morabatí..., p. 21.

83. Per la seua banda, Alfons X de Castella recorregué a la mutació dels tipus monetaris de billó per tal d'obtenir ingressos amb què escometre l'aixafament de la revolta musulmana, tot encunyant en 1265 els anomenats dineros alfonsies, blancas o moneda de la primera guerra: LADERO, M.A., «Monedas y políticas 
D'altra banda, com que també al regne de Mallorca corria oficialment la moneda valenciana l'establiment del monedatge l'afectava per igual, si més no teòricament, ja que no hi ha cap notícia del seu cobrament al llarg del segle XIII. De fet, malgrat que la carta d'instauració del morabatí valencià fa esment dels civium ac proborum hominum civitatis et regni Maioricarum, no hi ha constància de la seua presència física en la reunió amb el rei de 1266 , contràriament al que passa amb els de la ciutat de València i els d'unes quantes de les principals viles reials valencianes ${ }^{84}$. En tot cas, però, el pagament periòdic del monedatge s'acaba establint a terres balears en 1301, també en unes circumstàncies molt concretes, en aquest cas no relacionades directament amb la guerra, sinó, com han destacat Ricard Soto i Antoni Mas, amb l'aplicació de les Ordinacions de Jaume II, un pla de conjunt destinat a incrementar els ingressos de la monarquia a través de la reordenació de la colonització, el bastiment d'una nova estructura fiscal i la creació d'un sistema monetari propi igualment basat en el diner ternal ${ }^{85}$.

Així doncs, segons hem vist a totes les unitats polítiques de la Corona, l'assegurament o no de la immutabilitat monetària a través del pagament d'un tribut periòdic anà lligat a la relativa estabilitat que proporcionà la moneda ternal de billó com a moneda adequada al petit intercanvi. Amb tot, el catalitzador fonamental -circumstancial però necessari- fou un altre: la guerra. I, en concret, les guerres encapçalades pel rei com a cap suprem del poder feudal, les quals, al llarg del segle XIII, es convertiren en un element fonamental del creixement dels recursos i del poder de la monarquia.

Ultra això, el lideratge constant de campanyes bèl-liques i l'increment inherent de territoris sobre el qual el rei podia desplegar l'administració del seu poder contribuïren igualment a l'impuls de la monetització per part de la monarquia i al bastiment d'una estructura fiscal basada durant aquesta centúria en impostos directes, com les peites, les quèsties, les redempcions d'exèrcit o els monedatges, en contrast amb l'estratègia rendística de la resta de senyors feudals, cen-

monetarias en la Corona de Castilla (siglos XIII a XV)», a Moneda y monedas en la Europa Medieval..., p. $145-147$.

84. J. CoRTÉs (ed.), Liber privilegiorum civitatis et regni Valencie..., doc. 74 (14.IV.1266). Els prohoms de la ciutat de València esmentats en el privilegi són els quatre jurats Ferrer Matoses, Guillem de Porcià, Berenguer Samorera i Guillem Arnau, i els ciutadans Arnau Escrivà, Guillemó Escrivà, Arnau de Montroig, Bartomeu d'Ossal, Guillem de Bell-1loc, jurista, Berenguer Dalmau, Guerau Martí, Mengot de Boisà, Bernat Arnau, Bernat Dalmau, Ramon de Poblet, Ramon de Riusech, Berenguer de Plana, Bartomeu Dezpont, Ferrer de Piera, Pere Mercer, Romeu Pellicer, Tamarit i Gilabert. Per la vila de Xàtiva hi eren presents Pere de Bosch, Arnau de Montsó, Pere Guasch i Ponç Carbonell; per la de Morvedre, Robau de Voltorasch, Berenguer Clavell, Joan de Mora i Arnau Llorenç; i, per la de Borriana, Bernat Escrivà i Arnau de Juneda.

85. Sото, R., «Drets reials, renda feudal i circulació monetària a Mallorca al segle XIII», a Gaceta numismática, 137 (2000), p. 47-48; MAs, A., «Les ordinacions, una reforma agrària», a Jaume II i les ordinacions de l'any 1300, Mallorca, 2002, p. 151. 
trada encara en les demandes en espècie ${ }^{86}$. En aquest sentit, podem dir que al llarg dels regnats d'Alfons el Cast, Pere el Catòlic i Jaume I els reis no deixaren d'augmentar el seu poder, tant a l'interior dels seus regnes com a costa d'altres territoris exteriors, tot dirigint constants expedicions de càstig o conquesta, bastint els ciments d'una xarxa administrativa complexa i incrementant de forma notable els volums de renda ingressats. Per això, com va exposar Thomas $\mathrm{N}$. Bisson $^{87}$, la moneda i el crèdit esdevingueren ja a començaments del segle XIII dues de les principals eines emprades per la monarquia per a gestionar tot aquest procés. Així, els reis consolidaren el valor fiduciari de la seua moneda, la imposaren de manera general, i la utilitzaren com a forma preeminent de captura i repartiment de la riquesa, tant en la seua estratègia rendística com en el mètode d'organització de les campanyes militars i de jerarquització de l'ordre feudal, uns fets que, al seu torn i en consonància amb l'increment de la monetització requerit, consolidaren el préstec com a sistema preponderant de fer front a les seues despeses.

És per això que guerra, moneda i fiscalitat conformaren una trama entrelligada que fou a la base del desenvolupament del poder de la monarquia feudal. Amb tot, els reis hagueren de mesurar les seues forces amb la resta de poders en cada territori i en cada moment concret, amb resultats diversos. Per exemple, si bé la noblesa aragonesa, interessada a crear noves fonts de renda, consentí l'establiment del monedatge en 1236 per tal de finançar la conquesta de València, només trenta anys després la concentració del poder reial en aquell nou regne fou un dels motius fonamentals que motivaren la seua negativa a contribuir en la campanya murciana, com palesa la lluita per la validesa a terres valencianes dels Furs d'Aragó.

Aquests, a banda de nombroses prerrogatives senyorials, comportaven el repartiment de les rendes reials entre la noblesa a través del sistema de cavalleries vigent al regne aragonès, raons per les quals -entre d'altres- Jaume I creà i impulsà l'aplicació dels Furs de València, molt més proclius al seu poder. I precisament en 1261, només tres anys abans de demanar un nou impost general a l'Aragó, el rei havia declarat l'observança exclusiva i universal dels furs valencians al regne de València ${ }^{88}$, fet davant del qual els principals rics homes i cavallers aragonesos es plantaren, segons Zurita, no consintiendo en ello por ser aquel reino de la conquista de Aragón y que debía ser poblado a su fuero

86. Guinot, E., «El modelo de feudalismo repoblador: renta y señoríos en la Valencia medieval», a Señorío y feudalismo en la península ibérica, ss. XII-XIX, Saragossa, 1993, vol. 2, p. 513-525.

87. Bisson, T.N., «Las finanzas del joven Jaime I (1213-1228)», a Jaime I y su época. X Congreso de Historia de la Corona de Aragón, Saragossa, 1980, vol. I, p. 161-208.

88. J. CoRTÉs (ed.), Liber privilegiorum civitatis et regni Valencie..., doc. 63 (11.IV.1261). 
y repartido a los aragoneses por caballerías como se acostumbraba ${ }^{89}$. De fet, aquest malestar va ser expressat en les mateixes Corts de Saragossa de 1264 en què el rei sol·licità un subsidi per a la guerra de Múrcia, el que ajuda a explicar, tot plegat, la negativa total de la noblesa aragonesa a col·laborar, tant a Aragó com al regne de València ${ }^{90}$.

En contrast amb això, Jaume I trobà el suport del reialenc valencià encapçalat pels prohoms de la capital, que en la seua pugna amb la noblesa aragonesa eren els principals beneficiaris d'uns Furs de València que els garantien el control d'assumptes de cabdal importància com ara la justícia. D'aquesta manera, en el context determinat de l'expedició a terres murcianes, els prohoms ciutadans aprofitaren la necessitat de la monarquia dels recursos monetaris indispensables per a organitzar l'exèrcit, bo i emprant la fiscalitat com el seu principal element de negociació a l'hora de guanyar elements de poder. Al seu torn el rei, fent ús de la seua regalia monetària, no perdé l'ocasió d'imposar un tribut periòdic i perpetu, important en aquests moments en què la fiscalitat reial es basava fonamentalment en l'obtenció periòdica de subsidis i tributs directes.

Així doncs, l'impost del morabatí al regne de València fou gestat per la monarquia i el reialenc, mentre que la noblesa, majoritàriament aragonesa, en quedà al marge, sense ser present a la reunió parlamentària de 1266 ni a la signatura de la instauració del tribut ${ }^{91}$. Tot plegat, com hem vist, la imposició dels diferents monedatges territorials a la Corona d'Aragó estigué estretament imbricada amb les guerres escomeses per la monarquia i el desplegament del poder reial, tot produint desenllaços particulars en el temps i en les formes, en funció de les diverses relacions de poder establertes a cadascuna de les seues unitats polítiques.

89. Zurita, J., Anales de la Corona de Aragón..., Llibre III, cap. LXVI.

90. Ultra això, ja en la dècada de 1280 la noblesa aragonesa assaltà el conjunt de rendes reials, tot aconseguint rebre també el monedatge dels seus senyorius i limitant considerablement les contribucions fiscals obtingudes per la monarquia a terres aragoneses, a excepció d'aquelles procedents de les comunitats d'aldees de Calataiud, Daroca i Terol. Vegeu: BAYDAL, V., «La fiscalitat reial directa a la Corona d'Aragó durant el segle XIII. Una visió de conjunt», Congrés Any Jaume I, Barcelona, 31 de març al 4 d'abril de 2008, en premsa.

91. J. CoRTÉs (ed.), Liber privilegiorum civitatis et regni Valencie..., doc. 74 (14.IV.1266). 